\title{
Analysis of thermal performance of a car radiator employing nanofluid
}

\author{
Ghanbarali Sheikhzadeh", Mohammadhadi Hajilou, , , Hamed Jafarian ${ }^{3}$ \\ ${ }^{1}$ Department of Mechanical Engineering, University of Kashan, Kashan 87317-51167, Iran \\ ${ }^{2}$ Department of Mechanical Eng., Iran University of Science and Technology, Tehran 16848-13114, Iran \\ ${ }^{3}$ Department of Mechanical Eng., Tarbiat Modaress University, Tehran 14115-111, Iran
}

\section{Email address:}

Sheikhz@kashanu.ac.ir (G. Sheikhzadeh), Hajilou_mh@mecheng.iust.ac.ir (M. Hajilou), Hamed.jafarian@modares.ac.ir (H. Jafarian)

\section{To cite this article:}

Ghanbarali Sheikhzadeh, Mohammadhadi Hajilou, Hamed Jafarian. Analysis of Thermal Performance of a Car Radiator Employing Nanofluid. International Journal of Mechanical Engineering and Applications. Vol. 2, No. 4, 2014, pp. 47-51.

doi: $10.11648 /$ j.ijmea.20140204.11

\begin{abstract}
In this study, thermal performance of a car radiator with employment of Ethylene Glycol/copper nanofluid in disparate environmental conditions has been investigated. The governing equations for heat transfer in the car radiator have been written and solved by using a generated computer code in different environmental states and the changes in the output nanofluid temperature have been studied. It has been shown that by increasing the values of volume fraction of nano-particles and also, Reynolds number of inlet air, one can observe a raise in the values of overall heat transfer coefficient of the air side and the rate of heat transfer. Furthermore, it is observed that by adding nano-sized particles to the coolant fluid in radiator, one can significantly reduce its output temperature. In addition, it has been demonstrated that by adding 5\% of nano-particles to the coolant fluid, thermal performance of the radiator in a hot weather of $50^{\circ} \mathrm{C}$ can be better than its performance in the weather of $20^{\circ} \mathrm{C}$.
\end{abstract}

Keywords: Nanofluid, Thermal Performance, Car Radiator, Environmental Conditions, Numerical Analysis

\section{Introduction}

Technical improvement in car industries has augmented the need for engines with high efficiencies. High efficiency of an engine is not only dependant on its function, but also it relies on the optimal fuel consumption and lower production of pollution. Reducing the weight of a car with optimal design of its radiator is a necessity for ecological systems. Adding fins is one of the ways to increase the rate of cooling in automobile radiators, in which more amounts of surface for heat transfer is created and convection heat transfer of air can enhance. Nonetheless, this method has been the subject of study of many researchers in the past and has almost reached its limit. One of the other proposed ways to increase the rate of heat transfer in automobile radiators is the employment of a coolant fluid with high conductivity coefficient or augmentation of the conductivity in a common coolant fluid.

Due to the fact that the conduction coefficient of coolant fluids such as water or ethylene glycol is very low, increasing their conductivity has been the taken into consideration by numerous scientists. So far, there has been vast number of theoretical and experimental studies on enhancing the conduction heat transfer of a fluid by suspending very small particles in them, which is a new approach in thermal sciences. In this regard, Maxwell [1] did some experiments in which he added some particles in the size of micron and nano to the fluid. The problem encountered in these fluids was the fact that particles settled in the bottom of the tank and also the flow rate of fluid reduced. Furthermore, corrosion in the pipes and significant pressure drops in the flows were another disadvantages of these fluids.

In comparison with micron-sized particles, since nano-particles have a high ratio of area to volume, they can create more stable suspensions; therefore, they can highly reduce the amount of sediments in the pipes and channels. Adding metallic materials with the size of nano to common fluids such as water, ethylene glycol and industrial oil, was first presented by Choi [2]. In addition, studies have demonstrated that adding metallic particles to base fluids can notably result in the raise of conductivity in fluids [3.4]. 
Conceptions for heat transfer correlation of nanofluids are presented by Xuan and Roetzel [5]. In their work, they have suggested that nanofluid behaves more like a fluid rather than a conventional solid-fluid mixture and based on this approach, they have proposed two different approaches for deriving heat transfer correlation of the nanofluid. Furthermore, Wang and Mujumdar [6] have conducted a review on the heat transfer characteristics of nanofluids. They have claimed that further theoretical and experimental research investigations are needed to understand the heat transfer characteristics of nanofluids and identify new and unique applications for these fields.

Numerous numerical studies about the evaluation of the effect of using nanofluids in heat transfer devices have been carried out. Das, Choi and Patel [7] investigated the utilization of nanofluids in heat exchangers. They have reported that nanofluids show great promise for use in cooling and related technologies. Also, they have claimed that metallic nano-particles seem to enhance thermal conductivity anomalously, with very large enhancement at very low volume fraction. They claim that this finding opens the prospect of increasing thermal conductivity enhancement without making large changes in viscosity, which can erode the gain in convective conditions.

Moreover, Nguyen, Roy, Gauthier and Galanis[8] examined the employment of $\mathrm{Al} 2 \mathrm{O} 3$ /water nanofluid in a cooling system of electrical devices. They envisaged a significant improvement of heat transfer coefficient (around $40 \%$ ) for the $7 \%$ volume fraction of nano-particles.

It seems that nanofluids can be a good replacement for the coolant fluid in automobile radiators. Yu, France, Choi and Routbort [9] in a research on using nanotechnology in transportation have shown that $15 \%$ to $40 \%$ of heat transfer enhancement can be achieved by employing different nanofluids. Owing to this feature, one can reduce the size and weight of a car without any negative impact on its heat transfer rate [10]. Performance investigation of ethylene glycol/copper nanofluid as the coolant fluid in a car radiator has been studied by Leong, Saidur, Kazi and Mamnuc [11] and in their work, they have reported an enhancement of about $4 \%$ in the rate of heat transfer with adding $2 \%$ of nano-particles to the base fluid.

Recently, Fadhilah et al. [12] presented a mathematical modeling in order to study the thermo-physical properties of copper/water nanofluid for automotive cooling systems. They have showed in their work that by offering $10 \%$ of copper nano-particles concentration, the heat transfer coefficient of the nanofluid can be enhanced up to $92 \%$.

In the current research, thermal performance of a car radiator by using ethylene glycol/copper nanofluid with different volume fractions of nano-particles in disparate environmental conditions (changes in the velocity and temperature of air) is presented. In addition, changes in the overall heat transfer coefficient of the air side as well as the rate of heat transfer in terms of $\varphi$ (volume fraction of nano-particles) and Reynolds number of the inlet air have been demonstrated. Also, output temperature of nanofluid as a function of volume fraction of nano-particles is investigated.

\section{Problem Definition}

A sample radiator with general characteristics presented by [13] has been considered in Table 1. Also, its specific characteristics which is according to [14] is represented in Table 2. The considered radiator is a cross flow compact heat exchanger with unmixed fluids.

The flow of the Ethylene Glycol/copper nanofluid as the coolant fluid of engine runs through the radiator tubes as the hot fluid, and the flow of air as the cooling fluid is perpendicular to the finned pipes. Thermal performance of the radiator will be analyzed by considering equations governing the heat transfer and with changes in the volume fraction of nano-particles and the conditions of the incoming air to the radiator, the effect of employing nanofluids as the coolant fluid of the automobile radiator in disparate environmental conditions will be studied. Thermo-physical properties of air, ethylene glycol and copper have been demonstrated in Table 3.

\section{Governing Equations}

Assuming all the properties to be constant, equations governing heat transfer in both sides of air and nanofluid have been written. In these equations, subscripts a, nf, $\mathrm{f}$ and $\mathrm{p}$ donate characteristics of air, nanofluid, the base fluid and the particles, respectively.

Characteristics of nanofluid with respect to the ones of nano-particles and the base fluid as well as volume fraction of nano-particles can be computed through the following equations [16]:

$$
\begin{gathered}
\rho_{n f}=(1-\varphi) \rho_{f}+\varphi \rho_{p} \\
\left(\rho c_{p}\right)_{n f}=(1-\varphi)\left(\rho c_{p}\right)_{f}+\varphi\left(\rho c_{p}\right)_{p} \\
\mu_{n f}=\mu_{f}(1-\varphi)^{-2.5}
\end{gathered}
$$

Table 1. Characteristics of the sample Radiator [13]

\begin{tabular}{lll}
\hline Description & Air & Coolant \\
\hline Inlet Temperature $\left({ }^{\circ} \mathrm{C}\right)$ & $20-55$ & $70-95$ \\
Core width $(\mathrm{m})$ & 0.6 & - \\
Core height $(\mathrm{m})$ & 0.5 & - \\
Core depth $(\mathrm{m})$ & 0.4 & - \\
Tube size $(\mathrm{cm} \times \mathrm{cm})$ & - & $0.245-1.872$ \\
\hline
\end{tabular}

It should be pointed out that the conduction coefficient of ethylene glycol/copper nanofluid has been taken from [17].

Values of Reynolds number of both flows are presumed to be known. Thus, mass velocity of the two flows can be determined as follows:

$$
G_{a}=\mu_{a} \operatorname{Re}_{a} / D_{h, a}, G_{n f}=\mu_{n f} \operatorname{Re}_{n f} / D_{h, n f}
$$

Also, mass flow rate of nanofluid and air are: 


$$
\dot{m}_{a}=G_{a} A_{f r, a} \sigma_{a}, \dot{m}_{n f}=G_{n f} A_{f r, n f} \sigma_{n f}
$$

Table 2. Surface Characteristics of the sample Radiator [14]

\begin{tabular}{lll}
\hline Description & Air & Coolant \\
\hline Tube arrangement & Staggered & - \\
Fin type & Ruffled & - \\
Fin material & Copper & - \\
Fin pitch $(\mathrm{cm} /$ fin $)$ & 4.46 & - \\
Fin thickness $(\mathrm{cm})$ & 0.01 & - \\
Hydraulic diameter, Dh $(\mathrm{cm})$ & 0.351 & 0.373 \\
Free flow area frontal area, $\sigma$ & 0.78 & 0.129 \\
Heat transfer area/total volume $\left(\mathrm{m}^{2} / \mathrm{m}^{3}\right), \alpha$ & 0.886 & 0.129 \\
Fin area/total area, $\beta$ & 0.845 & - \\
\hline
\end{tabular}

Table 3. Thermo-physical properties of ethylene glycol, air and copper [15]

\begin{tabular}{llll}
\hline $\begin{array}{l}\text { Thermo-physical } \\
\text { property }\end{array}$ & $\begin{array}{l}\text { Copper } \\
(\mathbf{3 6 5} \mathbf{K})\end{array}$ & $\begin{array}{l}\text { Ethylene } \\
\text { Glycol (365K) }\end{array}$ & Air (365 K) \\
\hline $\begin{array}{l}\text { Heat Capacity } \mathrm{c}_{\mathrm{p}} \\
(\mathrm{J} / \mathrm{kg} . \mathrm{K})\end{array}$ & 387.98 & 2664 & 1007 \\
$\begin{array}{l}\text { Density } \rho\left(\mathrm{kg} / \mathrm{m}^{3}\right) \\
\begin{array}{l}\text { Conduction } \\
\text { Coefficient } \mathrm{k}\end{array}\end{array}$ & 8933 & 1076 & 1.1618 \\
$\begin{array}{l}\mathrm{W} / \mathrm{m} . \mathrm{K}) \\
\text { Viscosity } \mu\left(\mathrm{Ns} / \mathrm{m}^{2}\right)\end{array}$ & 399.4 & 0.261 & 0.0263 \\
\hline
\end{tabular}

Furthermore, the rates of heat capacity of the two aforementioned flows are:

$$
C_{a}=\dot{m}_{a} C_{p, a}, C_{n f}=\dot{m}_{n f} C_{p, n f}
$$

Comparing the values of the rates of heat capacity of the two flows, minimum and maximum rates of heat capacity and their ratio can be determined as:

$$
C^{*}=C_{\min } / C_{\max }
$$

Also, heat transfer coefficient of air can be calculated from the following equation:

$$
h_{a}=J_{a} G_{a} c_{p, a} / \operatorname{Pr}_{a}^{2 / 3}
$$

In which the Colburn factor, Ja, is:

$$
J_{a}=0.174 / \operatorname{Re}_{a}^{0.383}
$$

Moreover, total surface temperature effectiveness in the air side follows the subsequent equation:

$$
\eta_{o}=1-\left(1-\eta_{f i n}\right) \times A_{\text {fin }} / A
$$

In which the effectiveness of fins (assuming symmetry between the pipes) is:

$$
\eta_{f i n}=\tanh \left(m l_{f i n}\right) / m l_{f i n}, m=\sqrt{2 h_{a} / k_{f i n} t_{f i n}}
$$

Heat transfer coefficient of nanofluid can be determined by the equation (12):

$$
h_{n f}=N u_{n f} k_{n f} / D_{h, n f}
$$

Where Nusselt number stands for the fully-developed laminar flow which its value is:

$$
N u_{n f}=4.36
$$

Neglecting the sediment factor and thermal resistance in the pipes, the overall heat transfer coefficient based on the heat transfer surface in the air side can be expressed as in equation (14):

$$
\frac{1}{U_{a}}=\frac{1}{\eta_{o} h_{a}}+\frac{1}{h_{n f}\left(\alpha_{n f} / \alpha_{a}\right)}
$$

And the number of heat transfer units can also be expressed as:

$$
N T U=\frac{U_{a}\left(\alpha_{a} V\right)}{C_{\min }}
$$

In which $\mathrm{V}$ is the volume of the radiator.

Considering the values of $C^{*}$ and NTU calculated from equations (7) and (15), the efficiency of the radiator based on a cross-flow unmixed fluid heat exchanger can be determined from equation (16):

$$
\varepsilon=1-\exp \left\{\frac{1}{C^{*}} N T U^{0.22}\left[\exp \left(-C^{*} N T U^{0.78}\right)-1\right]\right\}
$$

And finally, the overall rate of heat transfer, $\mathrm{Q}$, is:

$$
Q=\varepsilon C_{\min }\left(T_{n f, i}-T_{a, i}\right)
$$

Which can be established by means of a thermal balancing between the two output temperatures of the two flows.

Calculations using a generated computer code for different conditions have been conducted and the results are illustrated in the subsequent part.

\section{Results and Discussion}

Some presumptions have been considered during the course of calculations, such as the Reynolds number and the inlet air temperature are assumed to have the constant values of 4000 and $37.5^{\circ} \mathrm{C}$, respectively, expect for the part in which the effect of changes in the conditions of the inlet air has been investigated. Mass flow rate of the coolant (nanofluid) is also assumed to be constant and equal to 7 $\mathrm{kg} / \mathrm{s}$ and its input temperature has been considered $82.5^{\circ} \mathrm{C}$. All the investigations have been carried out in the domain of 0 to $5 \%$ of volume fraction of nano-particles.

According to figure (1), the overall heat transfer coefficient of the air side raises with an increase in the volume fraction of nano-particles. It can be seen that with augmentation of $\varphi$ from 0 to $5 \%$, the overall heat transfer coefficient of the air side experiences an increase of about $64.3 \%$ in its values.

Furthermore, rate of heat transfer in terms of the volume fraction of nano-particles has been depicted in figure (2). 
As it is apparent in this figure, with a rise in the values of volume fraction of nano-particles from 0 to $5 \%$, the rate of heat transfer increases for $29.6 \%$.

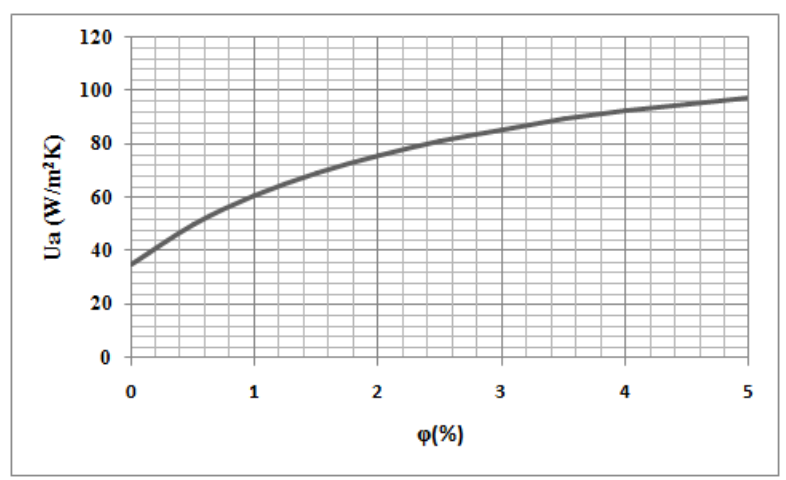

Figure 1. Overall heat transfer coefficient of the air side with respect to volume fraction of nano-particles

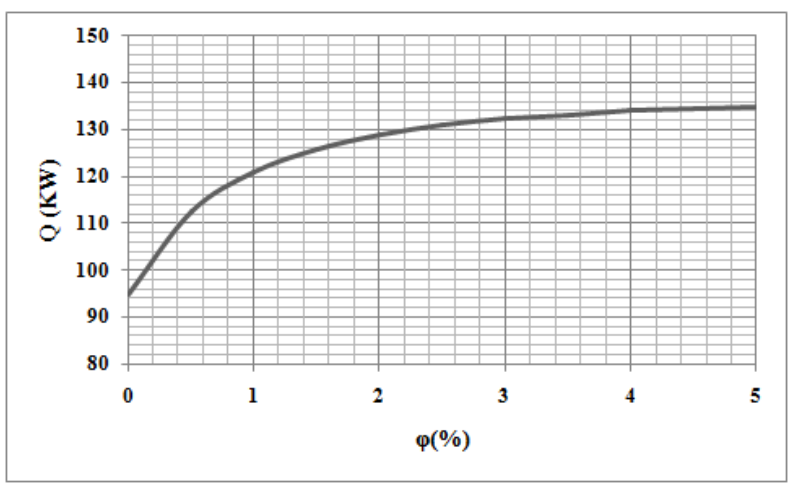

Figure 2. Effect of volume fraction of nano-particles on the rate of heat transfer

Now, changes on the inlet air to the radiator are investigated and results are expressed in figures (3) to (5).

In order to examine the effect of changes in the conditions of the inlet air of the radiator, firstly, the effect of changes in the Reynolds number of inlet air is studied. In figure (3), the overall heat transfer coefficient of the air side in terms of Reynolds number has been shown. As it has been demonstrated, the increase in the values of overall heat transfer coefficient of the air side for pure ethylene glycol is $4.5 \%$, whereas for nanofluid it is $12.4 \%$. Besides, as the volume fraction of nano-particles augments, not only their values of Ua increases, but also their rate of change experiences a raise in its values.

Figure (4) illustrates the changes in the rate of heat transfer with respect to Reynolds number of the inlet air. Enhancement of the Reynolds number will clearly result in a raise in the values of $\mathrm{Q}$, where the more the volume fraction of nano-particles, the more values of $\mathrm{Q}$ can be achieved. Also, it is noteworthy to point out that an increase in the rate of heat transfer with changes in Reynolds number of the inlet air is $26.16 \%$ for nanofluids while for pure ethylene glycol this value is $15.6 \%$. Moreover, according to figure (4), there seems to be a convergence in the values of $\mathrm{Q}$ as the volume fraction of nano-particles takes higher percentages.

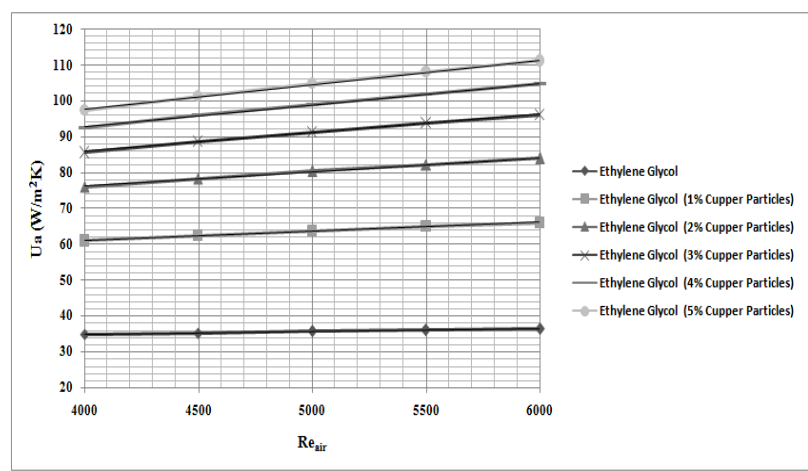

Figure 3. Changes in the overall heat transfer coefficient as a function of Reynolds number of the inlet air

The effect of changes of the inlet air temperature on the output nanofluid temperature (coolant fluid) has been shown in figure (5). It can be observed that with the inlet air becoming warmer, the output temperature of coolant will increase too. Besides, the temperature of the outgoing nanofluid from the radiator in terms of volume fraction of nano-particles reduces. This matter can be vividly seen in figure (5), where if the input temperature of air is $20^{\circ} \mathrm{C}$, by adding $5 \%$ of nano-particles, the temperature of the outgoing coolant fluid from the radiator can be decreased from $86.3^{\circ} \mathrm{C}$ to $78.7{ }^{\circ} \mathrm{C}$. On the other hand, if the inlet temperature of air augments to $50{ }^{\circ} \mathrm{C}$, by adding $5 \%$ of nano-particles, the output temperature of the coolant fluid can be reduced from $89.6{ }^{\circ} \mathrm{C}$ to $85.2{ }^{\circ} \mathrm{C}$. In other words, by adding $5 \%$ of nano-particles, the performance of the radiator in the hot weather of $50^{\circ} \mathrm{C}$ will even be better than that of $20^{\circ} \mathrm{C}$.

It should be pointed out that the attained results in this research are in reasonable agreement with the ones presented by Leong et al. [11], i.e. the trend of all the present figures are compatible with the presented results of [11]. Nonetheless, since the problem definition in the present work and the one in Leong et al. [11] is different, and also due to the fact that the attempt in this research has been more on the practical aspects of thermal performance of the car radiator rather than theoretical ones which are discussed by Leong et al. [11], some differences between the values of two works can be observed.

\section{Conclusion}

In this paper, thermal performance of a sample car radiator with employment of nanofluids in different environmental conditions has been investigated. According to the attained results, it could be seen that with augmentation of the volume fraction of nano-particles from 0 to $5 \%$, the overall heat transfer coefficient of the air side experiences an increase of about $64.3 \%$ in its values and the rate of heat transfer can raise about $26.9 \%$. Furthermore, as Reynolds number enhances from 4000 to 6000 , values of the overall heat transfer coefficient of the air side for pure ethylene glycol would increase $4.5 \%$, whereas for nanofluid this raise is $12.4 \%$. Moreover, the rate of heat transfer with changes in Reynolds number of the inlet air 
rises $26.16 \%$ for nanofluids while for pure ethylene glycol it is $15.6 \%$. In addition, by adding nano-particles to the base fluid, one can reduce the temperature of the outgoing coolant fluid from radiator. In particular, by adding $5 \%$ of nano-particles to the coolant fluid, performance of the radiator in the hot weather of $50^{\circ} \mathrm{C}$ can be even better than that of $20^{\circ} \mathrm{C}$.

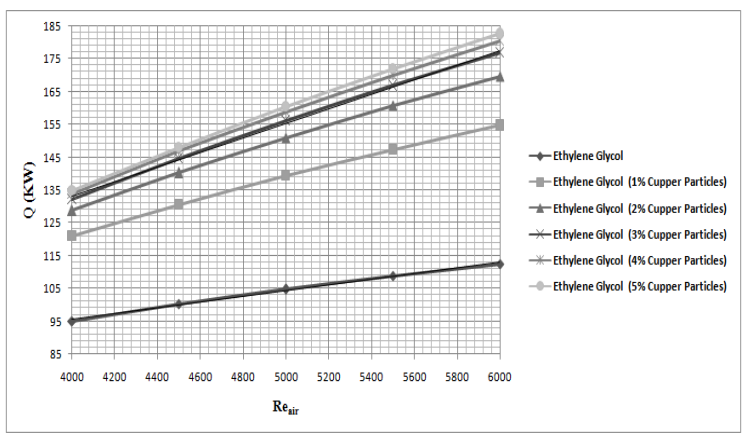

Figure 4. Rate of heat transfer as a function of Reynolds number of the inlet air

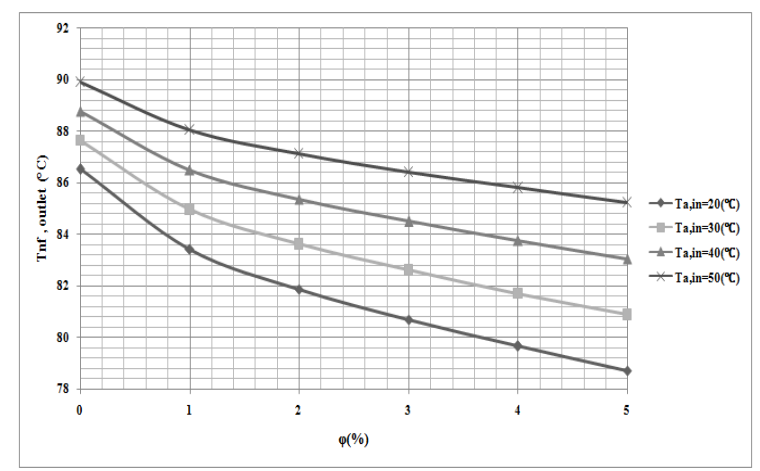

Figure 5. Output temperature of nanofluid as a function of volume fraction of nano-particles

\section{References}

[1] Maxwell, J.C., 1891. A Treatise on Electricity and Magnetism. Clarendon Press, Oxford, UK.

[2] Choi, S.U.S., 1995. "Enhancing thermal conductivity of fluids with nanoparticles". ASME, FED231/MD, 66, pp. 99-105.

[3] Lee, S., Choi, S.U.S., Li, S., and Eastman, J.A., 1999. "Measuring thermal conductivity of fluids containing oxide nanoparticles". Journal of Heat Transfer, 121, pp. 280-289.

[4] Das, S.K., Putra, N., Thiesen, P., and Roetzel, W., 2003. "Temperature dependence of thermal conductivity enhancement for nanofluids". Journal of Heat Transfer, 125, pp. 567-574.
[5] Xuan, Y., Roetzel, W. (2000) Conception for heat transfer correlations of nanofluids. International Journal of Heat and Mass Transfer 43, 3701-3707.

[6] Wang, X.Q., Mujumdar, A.S. (2007) Heat transfer characteristics of nanofluids: a review, International Journal of Thermal Sciences 46, 1-19.

[7] Das, S., Choi, S., and Patel, H., 2006. "Heat transfer in nanofluids - a review". Heat Transfer Eng, 27(10), pp. 3-19.

[8] Nguyen, C.T., Roy, G., Gauthier, C., and Galanis, N., 2007. "Heat transfer enhancement using Al2O3-water nanofluid for an electronic liquid-cooling system". Appl. Therm. Eng, 27(8-9), pp. 1501-1506.

[9] Yu, W., France, D.M., Choi, S.U.S., Routbort, J.L., 2007. "Review and Assessment of Nanofluid Technology for Transportation and Other Applications (No. ANL/ESD/07-9). Energy System Division, Argonne National Laboratory, Argonne.

[10] Kulkarni, D.P., Vajjha, R.S., Das, D.K., and Oliva, D., 2008. "Application of aluminum oxide nanofluids in diesel electric generator as jacket water coolant", Appl. Therm. Eng, 28(14-15), pp. 1774-1781.

[11] Leong, K.Y., Saidur, R., Kazi, S.N., Mamunc, 2010, "Performance investigation of an automotive car radiator operated with nanofluid-based coolants (nanofluid as a coolant in a radiator", Applied Thermal Engineering 30, pp. 2685-2692.

[12] Fadhilah, S.A., Hidayah, I., Hilwa, M.Z., Faizah, H.N., Marhamah, R. S. (2013) Thermophysical Properties of Copper/ Water Nanofluid for Automotive Cooling System Mathematical Modeling, Journal of Mechanical Engineering and Technology, 5(2), 27-39

[13] Vasu, V., Krishna, K.R., Kumar, A.C.S., 2008. "Thermal design analysis of compact heat exchanger using nanofluids", International Journal of Nanomanufacturing, 2 (3), pp. 271-287.

[14] Charyulu, D.G., Singh, G., Sharma, J.K., 1999. "Performance evaluation of a radiator in a diesel engine- a case study", Applied Thermal Engineering, 19, pp. 625-639.

[15] Incropera, F. P., DeWitt, D.P. (1996) Fundamentals of Heat and Mass Transfer, John Wiley \& Sons, New York

[16] Xuan, Y., and Li, Q., 2003. "Investigation on convective heat transfer and flow features of nanofluids". Journal of Heat Transfer, 125, pp. 151-155.

[17] Eastman, J.A., Choi, S.U.S., Li, S., Yu, W., Thompson, L.J., 2001, "Anomalously increased effective thermal conductivities of ethylene glycol-based nanofluids containing copper nanoparticles", Applied Physics Letters 78 (6), pp. 718-720. 